\title{
ANALYSIS OF DISCRIMINATORY GAME VARIABLES BETWEEN WINNERS AND LOSERS IN WOMEN'S HANDBALL WORLD CHAMPIONSHIPS FROM 2007 TO 2017
}

\author{
Leandro V. de Paula ${ }^{1,2}$, Flávia E. Costa ${ }^{1}$, Renato M. Ferreira ${ }^{1}$, Rafael P. Menezes ${ }^{3}$, \\ Francisco Z. Werneck ${ }^{1}$, Emerson F. Coelho ${ }^{1}$, and Pablo J. Greco ${ }^{2}$ \\ ${ }^{1}$ Sports Center, Federal University of Ouro Preto - UFOP, Ouro Preto, Brazil \\ ${ }^{2}$ School of Physical Education, Physical Therapy and Occupational Therapy, \\ Department of Sports, Federal University of Minas Gerais - UFMG, Belo Horizonte, Brazil \\ ${ }^{3}$ School of Physical Education and Sport of Ribeirão Preto, University of São Paulo - USP, \\ Ribeirão Preto, Brazil
}

\begin{abstract}
:
The aim of this study was to identify game variables that discriminated winning from losing teams and to understand how these variables contributed to victory by observing goal differences in matches of the women's handball world championships. The sample comprised 471 WCh's games played between 2007 and 2017. The games were grouped into three clusters: balanced games - difference of 1-8 goals; unbalanced games - difference of 9-20 goals; and very unbalanced games - difference of $>20$ goals. Generally, the performance of winning teams was significantly higher (in most variables), or lower in the case of the number of technical faults $(p<.05)$. In the balanced games, there was a greater contribution of defensive variables (stolen balls, blocked throws, and goalkeeper's efficiency indicators) in relation to attack variables (attack efficiency and throw efficiency indicators). For victory, the number of technical faults reduce the chances of winning. Games with the unbalanced and very unbalanced goal differences seem to follow the same tendency; however, in the very unbalanced games, there were more assists, yellow cards and 2-min suspensions. We concluded that the decisive variables for victory in the balanced games showed a greater weight, with a special emphasis on stolen balls followed by offensive variables (throw efficiency indicators, attack efficiency, and technical faults). There was an equal tendency for the games with the unbalanced and very unbalanced outcomes.
\end{abstract}

Key words: team handball, game analysis, static approach, tactics, team sports

\section{Introduction}

The search for excellence in handball requires from coaches and technical committees to seek for means and tools for a competitive performance analysis to identify the variables needed for success. Between 1995 and 2001, important changes in the rules of handball were discussed and implemented, such as the "passive play rule", related to a lack of objectivity in the attack, and "quick restart of the game after the goal conceded" (Karcher \& Buchheit, 2014; Seco, 2015). Essentially, because of such modifications and subsequent changes (such as the latest rule of the seventh player switched with the goalkeeper), the game has become faster, more dynamic and complex, with many changes in the intensity of players' actions. In this sense, a lack of information from game performance analyses on the variables that differentiate between the winning and losing teams makes it difficult to plan training aiming to improve performance in highlevel competitions; also, there is a lack of data that can serve as a reference for teams, coaches, and players in development (Karcher \& Buchheit, 2014; Prieto, Gómez, \& Sampaio, 2015).

Handball is a team sport characterized by intermittent physical efforts, played in a common space, where play is unfolding under the laws of withinteam cooperation and oppositional relationships between players of two teams. The context of individual and team actions developed in the game is to a great extent unpredictable, random, and variable (Menezes, 2012). Players behave in accordance with offensive (maintenance of ball possession, advance 
to the opponent's goal, and score) and defensive principles (recover ball possession, hinder the opponent's progression, and protect own target) (Bayer, 1994; Estriga \& Moreira, 2014).

The technical-tactical analysis of handball games unfolds usually in two categories called (1) dynamic analysis oriented to the process of games and (2) game-oriented static analysis (Prieto, et al., 2015; Volossovitch, 2013, 2017). The dynamic analysis records technical-tactical actions in a chronological order, providing a more complete and expanded view of tactical options as considers the context of actions, and is more complex methodologically (Pfeiffer \& Perl, 2006; Volossovitch, 2013; Prieto, et al., 2015). On the other hand, the static analysis focuses on the description and comparison of cumulative game variables of individual and team actions, as well as on the study of game patterns of winners and losers in competitions using multivariate approaches, without considering the context within actions occur (Volossovitch, 2013, 2017; Prieto, et al., 2015).

Studies describing and comparing game variables in high-level competitions have attributed the greatest prediction power for victory to the efficiency of different types of throws on goal (Bilge, 2012; Gruic, Vuleta, \& Milanovic, 2006; Lagos, Gómez, Viaño, González-Garcia, \& Fernández, 2013; Meletakos, Vagenas, \& Byaios, 2011; Ohnjec, Vuleta, Milanović, \& Gruić, 2008; Srhoj, Rogulj, Padovan, \& Katic, 2001; Vuleta, Milanovic, \& Sertic, 2003; Vuleta, Sporis, \& Milanovic, 2015), and the counter-attack efficiency (Gruic, et al., 2006; Rogulj, Vuleta, Milanovic, Cavala, \& Foretic, 2011; Oliveira \& Gomez, 2012; Srhoj, et al., 2001; Teles \& Volossovitch, 2015) in the offensive phase. However, diffuse results, observed predominantly in men's handball, can possibly be attributed to the analysis of games with different confrontation quality characteristics (univariate approach).

On the other hand, there seems to be little interest in the analysis of defensive variables, highlighting the efficiency of the goalkeeper (Gruic, et al., 2006; Lagos, et al., 2013; Volossovitch \& Gonçalves, 2003), ball retrieving and blocked throws (Lagos, et al., 2013). In addition, there seems to be a consensus on the importance of the general efficiency of the goalkeeper (Daza, Andrés \& Tarragó, 2017; Saavedra, Porgeirsson, Kristjánsdóttir, Chang, \& Halldórsson, 2017; Volossovitch \& Gonçalves, 2003) and stolen balls (Daza, et al., 2017), elements crucial to the beginning of the transition to attack.

Additionally, in game patterns analyses, the available evidence shows that counter-attack efficiency (Rogulj, Srhoj, \& Srhoj, 2004; Volossovitch \& Gonçalves, 2003), fast attacks lasting less than 25 seconds (Volossovitch \& Gonçalves, 2003), technical faults (Daza, et al., 2017; Saavedra, et al.,
2017), the efficiency of 9-meter throws (Volossovitch \& Gonçalves, 2003), general shot efficiency, number of attacks (Saavedra, et al., 2017), and number of shots defended by the opposing team (Daza, et al., 2017) are relevant performance indicators of the winning teams' play in attack. However, despite representative samples (80-324 games), such studies were performed only in men's handball and did not consider the characteristics of confrontations, manifested in the difference in the scored goals, observed in game outcomes (Daza, et al., 2017; Rogulj, et al., 2004; Saavedra, et al., 2017; Volossovitch \& Gonçalves, 2003).

Furthermore, to our knowledge, there is a lack of information emerging from the analysis of play patterns of winners and losers in high-level women's handball, suggesting the need for a greater focus on it (Volossovitch, 2013) and for considering the characteristics of confrontations. Therefore, the identification of performance indicators and behaviors that contribute to the success of a team is one of the latent issues in the tactical analysis of handball. In this sense, game analysis can offer a greater capacity for sports preparation for a future competitive scenario. Thus, the aim of this research was to analyze game variables that discriminated the winning teams from losing teams and to identify how these variables contributed to victory by considering the characteristics of confrontations in a way to observe goal differences in matches of women's handball world championships.

\section{Methods}

This study is a post-facto quasi-experimental study (Tenenbaum \& Driscoll, 2005) based on the official data of matches, provided by the International Handball Federation (IHF), for the women's handball world championships from 2007 to 2017.

\section{Sample}

Altogether, 489 women handball world championships' matches were played between 2007 and 2017 , corresponding to $39.4 \%$ of all matches played in all elite handball world championships $(1,242$ matches). Eighteen games that resulted in a tie were excluded from the sample. Therefore, the final study sample consisted of 471 games ( $37.9 \%$ of the total). In Table 1, the number of official matches played in each competition and the characteristics of age, body mass, and height of the athletes are presented.

\section{Procedures}

Data were retrieved from the online source of the International Handball Federation (IHF) (www. ihf.info). Game variables and results are available for download in the IHF website's competitions archive. The game statistics of the teams participating in the women's handball world champion- 
Table 1. Number of adult women's handball matches and general characteristics of the athletes in the 2007 to 2017 world championships

\begin{tabular}{llcccc}
\hline Year & Host (Champion) & Matches & Mass (kg) & Height (cm) & Age (years) \\
\hline 2007 & France (Russia) & 36 & $67.84 \pm 7.80$ & $174.71 \pm 7.02$ & $24.97 \pm 4.64$ \\
2009 & China (Russia) & 110 & $68.45 \pm 7.90$ & $174.63 \pm 7.17$ & $175.35 \pm 6.43$ \\
2011 & Brazil (Norway) & 88 & $68.68 \pm 7.72$ & $174.84 \pm 6.49$ \\
2013 & Serbia (Brazil) & 84 & $69.17 \pm 7.51$ & $175.35 \pm 6.97$ \\
2015 & Denmark (Norway) & 88 & $69.23 \pm 8.55$ & $175.78 \pm 2.04$ \\
2017 & Germany (France) & 83 & $70.04 \pm 2.24$ & $25.73 \pm 4.36$ \\
\hline \multicolumn{2}{l}{ Total (mean \pm standard deviation) } & 489 & $68.90 \pm 0.75$ & $175.11 \pm 0.45$ \\
\hline
\end{tabular}

Note. The data are available at the IHF website www.inf.info from the year 2007 to the year 2017.

Table 2. Variables proposed by the IHF and their meaning

\begin{tabular}{|c|c|}
\hline Game variable & Meaning \\
\hline Throw efficiency (TE) & $\begin{array}{l}\text { Percentage ratio between the number of goals scored and the number of throws } \\
\text { taken. }\end{array}$ \\
\hline Attack efficiency (AE) & Percentage ratio between the number of goals scored and the number of attacks. \\
\hline Efficiency of 6-m throws (E6T) & $\begin{array}{l}\text { Percentage ratio between the number of goals scored and the number of throws } \\
\text { executed from the line of } 6 \text { meters. }\end{array}$ \\
\hline Efficiency of wing throws (EWT) & $\begin{array}{l}\text { Percentage ratio between the number of goals scored and the number of throws from } \\
\text { wings' positions. }\end{array}$ \\
\hline Efficiency of 9-m throws (E9T) & $\begin{array}{l}\text { Percentage ratio between the number of goals scored and the number of throws taken } \\
\text { from and farther from the line of } 9 \text { meters (long range shots). }\end{array}$ \\
\hline Efficiency of 7-m throws (E7T) & $\begin{array}{l}\text { Percentage ratio between the number of goals scored and the number of throws taken } \\
\text { from the line of } 7 \text { meters. }\end{array}$ \\
\hline Fastbreak efficiency (FE) & $\begin{array}{l}\text { Percentage ratio between the number of goals scored and the number of fastbreaks } \\
\text { executed by each team. }\end{array}$ \\
\hline Breakthrough efficiency (BE) & $\begin{array}{l}\text { Percentage ratio between the number of goals scored and the number of } \\
\text { breakthroughs performed by each team. }\end{array}$ \\
\hline Assists (ASS) & $\begin{array}{l}\text { Absolute frequency of assists by a team. Assist is a pass the shooter receives to throw } \\
\text { on goal and score, i.e. a pass directly contributing to a field goal scored. }\end{array}$ \\
\hline Technical faults (TF) & Absolute frequency/number of technical errors made by a team. \\
\hline Steals (ST) & Absolute frequency/number of stolen balls by a team. \\
\hline Blocked throws (BT) & Absolute frequency/number of the opponent's throws on goal blocked by a team. \\
\hline Yellow cards (YC) & Yellow cards awarded by the referee for each team. \\
\hline 2-minute punishments (P2) & Punishments of 2 minutes (suspensions) conferred by the refereeing for each team. \\
\hline Goalkeeper efficiency (GE) & $\begin{array}{l}\text { Percentage ratio between the number of goalkeeper's saves and the number of } \\
\text { throws. }\end{array}$ \\
\hline $\begin{array}{l}\text { Efficiency of 6-m goalkeeper's } \\
\text { defenses (E6G) }\end{array}$ & $\begin{array}{l}\text { Percentage ratio between the number of the goalkeeper's saves of } 6-\mathrm{m} \text { line throws } \\
\text { and the number of throws made from } 6 \text { meters. }\end{array}$ \\
\hline $\begin{array}{l}\text { Efficiency of wings goalkeeper's } \\
\text { defenses (EWG) }\end{array}$ & $\begin{array}{l}\text { Percentage ratio between the number of the goalkeepers' saves of wing throws and } \\
\text { the number of wing throws. }\end{array}$ \\
\hline $\begin{array}{l}\text { Efficiency of } 9 \text { meters goalkeeper's } \\
\text { defenses (E9G) }\end{array}$ & $\begin{array}{l}\text { Percentage ratio between the number of the goalkeeper's saves of 9-m line throws } \\
\text { and the number of throws made from and farther from the } 9 \text {-meter line. }\end{array}$ \\
\hline $\begin{array}{l}\text { Efficiency of 7-m goalkeeper's } \\
\text { defenses (E7G) }\end{array}$ & $\begin{array}{l}\text { Percentage ratio between the number of the goalkeeper's saves of the } 7-\mathrm{m} \text { throws and } \\
\text { the number of throws made from } 7 \text { meters. }\end{array}$ \\
\hline $\begin{array}{l}\text { Efficiency of fastbreaks goalkeeper's } \\
\text { defenses (EFG) }\end{array}$ & $\begin{array}{l}\text { Percentage ratio between the number of the goalkeeper's saves of throws from } \\
\text { fastbreaks and the number of fastbreak throws. }\end{array}$ \\
\hline $\begin{array}{l}\text { Efficiency of breakthroughs } \\
\text { goalkeeper's defenses (EBG) }\end{array}$ & $\begin{array}{l}\text { Percentage ratio between the number of the goalkeeper's saves of the throws from } \\
\text { breakthroughs and the number of throws made from breakthroughs. }\end{array}$ \\
\hline
\end{tabular}

ships from 2007 to 2017 were extracted and tabulated in a spreadsheet (Microsoft Excel ${ }^{\circledR}$ ) (Table 2). In each game, the winning and the losing teams were identified. Then, the matches were classified according to the difference in the number of goals into: balanced games (1-8 goals), unbalanced 
games (9-20 goals), and very unbalanced games $(>$ 20 goals).

\section{Statistical analysis}

The descriptive statistics are presented in terms of means and standard deviations (mean $\pm \mathrm{SD}$ ) (Tables 1 and 3). Then, a cluster analysis was performed using k-means to define the cut-off point of goal differences between the matches by computing the partition coefficient $\left(\mathrm{R}^{2}\right)$. A priori, three clusters were defined (balanced games, unbalanced games, very unbalanced games) (Prieto, Gómez, Volossovitch, \& Sampaio, 2016). Previously, the assumptions of normality (Shapiro-Wilk test) and homoscedasticity (Bartlett test) were tested. When any of the assumptions was violated, a logarithmic transformation was performed, and the normality and homoscedasticity tests were performed again. To test the differences in game statistics between the winning and losing teams within each cluster, an analysis of variance (one-way ANOVA) was performed for the variables that respected such assumptions, and the nonparametric Mann-Whitney test for those that did not respect such assumptions.

Before the use of discrimination methods, the method of selecting the "stepwise" variables was used by observing the lowest measurement value of the Akaike Information Criterion (AIC) (Mingotti, 2013; Massuça, Fragoso, \& Teles, 2013). Then, to identify the variables that discriminated the winning from losing teams in groupings, a Fischer linear discriminant analysis was performed using the cross-validation method. The discriminant value for the structural coefficient (SC) was $\geq|0.30|$ (Lorenzo, Gómez, Ortega, Ibáñez, \& Sampaio, 2010). Finally, logistic regression models were fitted to estimate the probability of victory and the relative importance of each explanatory variable within each cluster. To verify the quality of the adjusted models, the residual deviance of the model was calculated. The significance level was $\mathrm{a}=.05$. For the tests, the statistical software "R" ("R" Foundation for Statistical Computing), version 3.3.0, was used.

\section{Results}

The studied variables are described in terms of means and standard deviations for each cluster (Table 3). In the balanced games, there were significant differences in most variables in favor of the winning teams (TE, AE, E6T, EWT, E9T, E7T, BE, ASS, ST, BT, P2, GE, E6G, EWG, EBG, E7G),

Table 3. Descriptive analysis of game variables studied in terms of mean and standard deviation (mean $\pm S D)(* I n d i c a t e s ~ s i g n i f i c a n t$ diferences for $p<.05$ )

\begin{tabular}{|c|c|c|c|c|c|c|c|c|c|}
\hline \multirow[t]{2}{*}{ INDEX } & \multicolumn{3}{|c|}{$\begin{array}{c}\text { Balanced games } \\
\text { (CLUSTER } 1 ; 1-8 \text { goals, } n=264 \text { ) }\end{array}$} & \multicolumn{3}{|c|}{$\begin{array}{l}\text { Unbalanced games } \\
\text { (CLUSTER 2; } 9-20 \text { goals, } n=146 \text { ) }\end{array}$} & \multicolumn{3}{|c|}{$\begin{array}{c}\text { Very unbalanced games } \\
\text { (CLUSTER } 3,>20 \text { goals, } n=61 \text { ) }\end{array}$} \\
\hline & Winner & Loser & Statistic; $p-$ value & Winner & Loser & Statistic; $p$ - value & Winner & Loser & Statistic; $p$ - value \\
\hline TE & $59.0 \pm 7.0$ & $50.9 \pm 7.2$ & $F=168.8 ; p<.001^{*}$ & $65.4 \pm 6.4$ & $42.3 \pm 7.6$ & $U=198.5 ; p<.001^{*}$ & $70.7 \pm 10.5$ & $31.1 \pm 9.2$ & $U=61 ; p<.001^{*}$ \\
\hline $\mathrm{AE}$ & $47.6 \pm 6.0$ & $40.9 \pm 6.6$ & $U=15128 ; p<.001^{*}$ & $53.7 \pm 6.3$ & $31.8 \pm 6.8$ & $U=277 ; p<.001^{*}$ & $61.9 \pm 6.8$ & $21.6 \pm 8.6$ & $U=44.5 ; p<.001^{*}$ \\
\hline E6T & $64.9 \pm 18.3$ & $57.4 \pm 20.4$ & $U=26842 ; p<.001^{*}$ & $67.5 \pm 16.5$ & $50.5 \pm 20.1$ & $U=5401.5 ; p<.001^{*}$ & $74.9 \pm 15.7$ & $45.3 \pm 20.1$ & $F=81.6 ; p<.001^{*}$ \\
\hline EWT & $61.4 \pm 22.0$ & $52.1 \pm 24.5$ & $U=25553 ; p<.001^{*}$ & $63.4 \pm 20.9$ & $40.5 \pm 26.5$ & $U=5203 ; p<.001^{*}$ & $65.7 \pm 20.5$ & $32.2 \pm 22.5$ & $U=491 ; p<.001^{*}$ \\
\hline E9T & $39.8 \pm 14.8$ & $33.6 \pm 14.2$ & $U=25450 ; p<.001^{*}$ & $45.6 \pm 20.1$ & $26.2 \pm 11.1$ & $U=3876.5 ; p<.001^{*}$ & $49.8 \pm 22.6$ & $16.2 \pm 9.9$ & $U=333 ; p<.001$ * \\
\hline E7T & $72.6 \pm 25.9$ & $67.3 \pm 27.3$ & $U=30727 ; p=.017^{*}$ & $73.9 \pm 25.4$ & $65.5 \pm 31.4$ & $U=9277 ; p=.049^{*}$ & $76.5 \pm 26.7$ & $51.5 \pm 39.0$ & $U=1169.5 ; p<.001^{*}$ \\
\hline FE & $75.1 \pm 23.2$ & $71.7 \pm 26.4$ & $U=32800 ; p=.235$ & $77.6 \pm 12.4$ & $55.7 \pm 37.6$ & $U=7474.5 ; p<.001^{*}$ & $78.4 \pm 9.6$ & $37.9 \pm 40.2$ & $U=834 ; p<.001^{*}$ \\
\hline $\mathrm{BE}$ & $74.6 \pm 31.5$ & $65.4 \pm 35.1$ & $U=29666 ; p=.002^{*}$ & $73.5 \pm 32.9$ & $63.6 \pm 39.5$ & $U=9361.5 ; p=0.06$ & $76.3 \pm 30.2$ & $53.9 \pm 41.4$ & $U=1332 ; p<.001^{*}$ \\
\hline ASS & $13.0 \pm 4.6$ & $10.7 \pm 4.3$ & $U=24986 ; p<.001^{*}$ & $17.2 \pm 5.5$ & $8.5 \pm 4.0$ & $U=1924 ; p<.001^{*}$ & $23.5 \pm 7.3$ & $5.4 \pm 3.4$ & $U=30.5 ; p<.001^{*}$ \\
\hline TF & $14.9 \pm 4.5$ & $15.8 \pm 4.5$ & $U=38406 ; p=.041^{*}$ & $14.6 \pm 4.5$ & $20.7 \pm 6.1$ & $U=16943 ; p<.001^{*}$ & $12.7 \pm 5.0$ & $27.8 \pm 7.6^{*}$ & $U=3557.5 ; p<.001^{*}$ \\
\hline ST & $4.3 \pm 2.5$ & $3.8 \pm 2.4$ & $U=31199 ; p=.035^{*}$ & $6.4 \pm 3.7$ & $3.6 \pm 2.6$ & $U=5596.5 ; p<.001^{*}$ & $7.9 \pm 3.9$ & $3.1 \pm 2.0$ & $U=409 ; p<.001^{*}$ \\
\hline BT & $3.3 \pm 2.5$ & $2.1 \pm 1.9$ & $U=25074 ; p<.001^{*}$ & $4.0 \pm 2.7$ & $1.3 \pm 1.3$ & $U=3761 ; p<.001^{*}$ & $6.7 \pm 3.5$ & $0.5 \pm 0.8$ & $\mathrm{U}=67 ; \mathrm{p}<.001^{*}$ \\
\hline YC & $2.9 \pm 0.7$ & $2.8 \pm 0.8$ & $U=34675 ; p=.916$ & $2.7 \pm 0.7$ & $2.6 \pm 0.9$ & $U=10128 ; p=.415$ & $2.5 \pm 0.7$ & $2.6 \pm 0.5$ & $U=2006 ; p=0.377$ \\
\hline P2 & $3.9 \pm 1.8$ & $3.6 \pm 1.8$ & $U=31207 ; p=.035^{*}$ & $3.3 \pm 2.0$ & $3.5 \pm 1.9$ & $U=11276 ; p=.3869$ & $1.7 \pm 1.5$ & $3.5 \pm 1.8$ & $U=2866.5 ; p<.001^{*}$ \\
\hline GE & $35.3 \pm 8.0$ & $27.7 \pm 7.3$ & $F=126.40 ; p<.001^{*}$ & $43.3 \pm 9.5$ & $22.5 \pm 6.5$ & $U=558 ; p<.001^{*}$ & $53.6 \pm 10.4$ & $18.3 \pm 5.3$ & $F=552.4 ; p<.001^{*}$ \\
\hline E6G & $33.0 \pm 20.0$ & $26.42 \pm 16.9$ & $U=27598 ; p<.001^{*}$ & $38.5 \pm 20.2$ & $23.8 \pm 15.5$ & $U=5967 ; p<.001^{*}$ & $40.3 \pm 21.5$ & $18.7 \pm 13.2$ & $U=694 ; p<.001^{*}$ \\
\hline EWG & $39.1 \pm 25.5$ & $29.6 \pm 21.4$ & $U=27387 ; p<.001^{*}$ & $47.9 \pm 29.8$ & $26.0 \pm 21.3$ & $U=5964 ; p<.001^{*}$ & $58.1 \pm 26.1$ & $23.7 \pm 19.1$ & $U=521 ; p<.001^{*}$ \\
\hline E7G & $24.5 \pm 24.3$ & $17.3 \pm 21.1$ & $U=28771 ; p<.001^{*}$ & $24.7 \pm 28.1$ & $15.6 \pm 20.4$ & $U=8802 ; p=.008^{*}$ & $25.5 \pm 33.6$ & $11.7 \pm 19.1$ & $U=1526 ; p=0.06$ \\
\hline E9G & $46.1 \pm 19.0$ & $39.6 \pm 19.2$ & $U=27578 ; p=.667$ & $55.7 \pm 16.7$ & $31.9 \pm 21.4$ & $U=3775 ; p<.001^{*}$ & $70.1 \pm 16.1$ & $26.9 \pm 24.9$ & $U=308 ; p<.001^{*}$ \\
\hline EFG & $18.6 \pm 22.7$ & $15.8 \pm 18.9$ & $U=33421 ; p=.393$ & $19.1 \pm 25.9$ & $15.0 \pm 10.51$ & $U=11642 ; p=.161$ & $29.0 \pm 38.9$ & $14.1 \pm 7.9$ & $U=2058 ; p=0.306$ \\
\hline EBG & $20.1 \pm 27.1$ & $12.5 \pm 20.4$ & $U=29755 ; p<.001^{*}$ & $16.8 \pm 27.3$ & $12.5 \pm 21.3$ & $U=10218 ; p=.475$ & $16.9 \pm 27.6$ & $9.1 \pm 14.6$ & $U=1717.5 ; p=0.392$ \\
\hline
\end{tabular}

Note. F - Test Statistics (Fisher); U - Test Statistics (Mann-Whitney). 
except for FE, YC, E9G, and in only one variable in favor of the losing teams (technical faults, TF). In the unbalanced games, there were again significant differences in favor of the winning teams (TE, AE, E6T, EWT, E9T, E7T, FE, BE, ASS, ST, BT, GE, E6G, EWG, E9G, E7G), and only one in favor of the losing teams (TF). Significant differences were not obtained only for BE, YC, P2, EFG, and EBG. For the very unbalanced games, no significant differences were obtained for $\mathrm{YC}, \mathrm{E} 7 \mathrm{G}, \mathrm{EFG}$, and $\mathrm{EBG}$, whereas in all the other quantified variables significant differences were determined either in favor of the winning teams (TE, AE, E6T, EWT, E9T, E7T, FE, BE, ASS, ST, BT, P2, GE, E6G, EWG and $\mathrm{E} 9 \mathrm{G})$, or the losing teams (TF).

The number of three clusters was determined in advance to minimize the sum of squares of residuals and to increase the value of $\mathrm{R}^{2}(85.7 \%)$, which indicated a greater heterogeneity among the groups, resulting in a larger sum of squares between the groups and, consequently, a greater homogeneity of the games allocated in each cluster. Table 4 shows the number of games classified in each cluster by the k-means method. After the application of the variable selection method (stepwise), the explanatory variables TE, EWT, AE, TF, ST, BT, YC, and $\mathrm{GE}(\mathrm{AIC}=-1,111.2)$ were maintained in the cluster 1 (balanced games), the variables TE, AE, TF, ST, BT, P2, and GE (AIC=-983.09) were maintained in cluster 2 (unbalanced games), and the variables AE, ASS, TF, ST, BT, YC, P2, and GE (AIC $=-512.93)$ were maintained in cluster 3 (very unbalanced games) for the construction of the models.

According to the established criterion $(\mathrm{SC} \geq|.30|)$, only the variable ST had a greater importance for the balanced games than the others. For the unbalanced games, the variables ST, BT, GE, TE, and AE showed, in the descending order, a greater importance for the discrimination of winners. For the very unbalanced games, there was a greater importance of the variables $\mathrm{YC}, \mathrm{P} 2, \mathrm{GE}, \mathrm{BT}, \mathrm{AE}, \mathrm{ASS}$, and ST, according to the values obtained for the $\mathrm{CE}$, which resulted with their greater contribution, in that order, to the score of the discriminant function of the winners. It is interesting to note that the ST variable was common to all the discriminant analyses performed. The structural coefficients obtained in the discriminant analyses and the proportion of correct classifications (\%) observed with the use of cross validation are shown in Table 4.

After the calculation of the residual deviance and the associated probability, we found that the obtained logistic regression models were adequate ( $p>05$ ), and the number of degrees of freedom (df) was greater than the deviance value (Table 5). For the interpretation of the created models, it was necessary to calculate the exponential value of the obtained coefficients (Odds Ratio; OR) for each model, as presented in Table 5 .

In this sense, the increase by $1 \%$ in the TE and $\mathrm{AE}$ increased the odds ratio of winning in the balanced games by $16.37 \%$ and $18.44 \%$, respectively, regarding the attack actions (considering the other variables remained unchanged). For the variables related to defense, each increase of one unit raised the odds ratio of winning in ST by $35.87 \%$ and in BT by $26.46 \%$. Additionally, considering the other variables remained constant, the $1 \%$ increase in GE increased the chance of a team to win by $25.81 \%$. On the other hand, by keeping the remaining variables (TE, AE, ST, BT, and GE) unchanged, the increment of one TF unit decreased the OR of winning by $6.66 \%$ in the balanced games. Table 5 shows the OR for each component variable

Table 4. Structural coefficients (SC) of the linear discriminant analysis of the official variables in balanced, unbalanced and very unbalanced games after the application of the variable selection methods by clusters. (Discriminant value of the $S C \geq|.30|$ in balanced games ${ }^{a}$, unbalanced games ${ }^{*}$ and very unbalanced games")

\begin{tabular}{|c|c|c|c|c|c|}
\hline \multicolumn{2}{|c|}{$\begin{array}{l}\text { CLUSTER } 1 \text { (1-8 goals) } \\
\text { Balanced games }\end{array}$} & \multicolumn{2}{|c|}{$\begin{array}{c}\text { CLUSTER } 2 \text { (9-20 goals) } \\
\text { Unbalanced games }\end{array}$} & \multicolumn{2}{|c|}{$\begin{array}{l}\text { CLUSTER } 3 \text { (>20 goals) } \\
\text { Very unbalanced games }\end{array}$} \\
\hline VARIABLES & SC & VARIABLES & sc & VARIABLES & SC \\
\hline TE & -.13 & TE & $-.33^{*}$ & $\mathrm{AE}$ & $-.64^{\dagger}$ \\
\hline $\mathrm{AE}$ & -.17 & $\mathrm{AE}$ & $-.31^{*}$ & ASS & $-.55^{\dagger}$ \\
\hline EWT & -.01 & TF & .19 & TF & .19 \\
\hline TF & .07 & ST & $-.55^{*}$ & ST & $-.53^{\dagger}$ \\
\hline ST & $-.30^{a}$ & BT & $-.49^{*}$ & BT & $-.67^{\dagger}$ \\
\hline BT & -.21 & $\mathrm{P} 2$ & -.16 & YC & $-2.75^{\dagger}$ \\
\hline YC & -.24 & GE & $-.42^{*}$ & $\mathrm{P} 2$ & $1.12^{\dagger}$ \\
\hline GE & -.22 & - & - & GE & $-.71^{\dagger}$ \\
\hline $\begin{array}{c}\text { Correct } \\
\text { Classifications }\end{array}$ & $86.0 \%$ & $\begin{array}{c}\text { Correct } \\
\text { Classifications }\end{array}$ & $99.3 \%$ & $\begin{array}{c}\text { Correct } \\
\text { Classifications }\end{array}$ & $99.2 \%$ \\
\hline Sample (\%) & $264(56.05 \%)$ & Sample (\%) & $146(30.99 \%)$ & Sample (\%) & 61 (12.95\%) \\
\hline
\end{tabular}

Note. TE - throws efficiency; AE - attack efficiency; EWT - efficiency of wing throws; TF - technical faults; ASS - assists; ST steals; BS - blocked shots; YC - yellow cards; P2 - 2-minute punishments; GE - goalkeeper efficiency. 
Table 5. Odd ratios (OR) of predictive variables and residual deviance (RD) of the logistic regression models

\begin{tabular}{|c|c|c|c|c|}
\hline CLUSTER & VARIABLES & OR $(95 \% \mathrm{CI})$ & SE & $\begin{array}{c}\text { DR } \\
\text { (DF, p-value) }\end{array}$ \\
\hline \multirow{7}{*}{$\begin{array}{l}\text { Balanced games } \\
\text { (1-8 goals) }\end{array}$} & Intercept & $4.17 * 10^{-11}\left(4.21 * 10^{-13}-4.13 * 10^{-9}\right)$ & 2.345 & \multirow{7}{*}{$\begin{array}{c}346.31 \\
(522, p=.99)\end{array}$} \\
\hline & TE & $1.163(1.066-1.27)$ & .044 & \\
\hline & $\mathrm{AE}$ & $1.184(1.057-1.327)$ & .058 & \\
\hline & $\mathrm{TF}$ & $.933(.836-1.042)$ & .056 & \\
\hline & ST & $1.358(1.196-1.542)$ & .064 & \\
\hline & BT & $1.264(1.110-1.441)$ & .067 & \\
\hline & GE & $1.258(1.200-1.316)$ & .023 & \\
\hline \multirow{4}{*}{$\begin{array}{l}\text { Unbalanced games } \\
\text { (9-20 goals) }\end{array}$} & Intercept & $.003(.001-.011)$ & .572 & \multirow{4}{*}{$\begin{array}{c}58.26 \\
(288, p=.99)\end{array}$} \\
\hline & $\mathrm{AE}$ & $1.070(1.050-1.090)$ & .009 & \\
\hline & ST & $1.058(1.014-1.104)$ & .021 & \\
\hline & GE & $1.033(1.019-1.046)$ & .006 & \\
\hline \multirow{3}{*}{$\begin{array}{l}\text { Very unbalanced games } \\
\text { (>20 goals) }\end{array}$} & Intercept & $.010(.002-.047)$ & .766 & \multirow{3}{*}{$\begin{array}{c}16.24 \\
(119, p=.99)\end{array}$} \\
\hline & $\mathrm{AE}$ & $1.049(1.024-1.076)$ & .012 & \\
\hline & GE & $1.026(1.004-1.048)$ & .011 & \\
\hline
\end{tabular}

Note. TE - throws efficiency; AE - attack efficiency; TF - technical faults; ST - steals; BS - blocked shots; GE - goalkeeper efficiency; $\mathrm{Cl}$ - confidence interval; DF - degrees of freedom; SE - standard error.

of the logistic regression models obtained for the balanced games.

In the unbalanced games, a $1 \%$ increase in $\mathrm{AE}$ increased the odds of winning by $7.0 \%$, considering that the value of the other variables remained constant. In these games, the increase in one unit of ST resulted in an increase in the OR of winning by $5.8 \%$. For the goalkeeper, a $1 \%$ increase in GE meant an increase by $3.3 \%$ in the winning ratio. Finally, for the very unbalanced games, the $1 \%$ increase in $\mathrm{AE}$ indicated a $5.0 \%$ increase in the winning odds ratio, if the value of the GE variable remained constant. On the other hand, by upkeeping the $\mathrm{AE}$ variable unchanged, the $1 \%$ increase in $\mathrm{GE}$ increased the odds of winning by $2.65 \%$. Table 5 shows the odds of winning for each component variable of the logistic regression models obtained for the unbalanced and very unbalanced games.

\section{Discussion and conclusions}

This study has identified game variables that discriminate the winning from the losing teams and how these variables contribute to victory in high-level women's handball, considering the characteristics of confrontations (goal differences in all matches) at the 2007-2017 world championships according to the data made available by the IHF. In summary, to our knowledge, this is the first study on high-level women's handball using a highly representative sample and a multivariate approach. This shows that, in the balanced games, there is a greater contribution of the defensive variables stolen balls, blocked throws and goalkeeper's efficiency, when compared to the offensive variables of attack efficiency and throw/shot efficiency, to predicting victory, with a particular emphasis on steals. On the other hand, among the offensive variables, the number of technical faults reduce the chances of winning.

In general, comparisons of the established means revealed that the performance of winning teams was significantly higher in most variables, whereas it was lower in case of the number of technical faults in each cluster (Table 3). The said does not apply for the variables YC (all clusters), P2 (unbalanced games), BE (unbalanced games), FE (balanced games), EFG (all clusters), EBG (unbalanced and very unbalanced games), E7C (very unbalanced games), and E9C (balanced games), which did not present significant differences between the winning and losing teams. Possibly, the separation of games into clusters and their homogeneity may explain broader differences between the winners and losers (Table 3 ) found in the present study in relation to previous studies that highlighted differences in the efficiency of throws on goal (Bilge, 2012; Gruic, et al., 2006; Lagos, et al., 2013; Meletakos, et al., 2011; Ohnjec, et al., 2008; Oliveira \& Gomez, 2012; Rogulj, et al., 2011; Srhoj, et al., 2001; Teles \& Volossovitch, 2015; Vuleta, et al., $2003,2015)$. The classification of games by goal difference resulted in three groups of games with homogeneous characteristics $\left(\mathrm{R}^{2}=85.7 \%\right)$, which may have led to a broader significance of differences than in previous studies, showing progressively greater differences among the means of variables from cluster 1 to cluster 3 (see Table 3).

When comparing our findings to other studies with the same purpose and approach to men's handball, we can notice certain differences. Saavedra et 
al. (2017) studied men's handball at the Olympic Games from 2004 to 2016 using a linear discriminant analysis ( $83 \%$ of correct rankings), and found that throw/shot efficiency, blocked throws or throws saved by the goalkeeper, technical faults and number of attacks differed (in descending order) the winning from the losing teams. These results diverge completely from our findings on the balanced games, where the variable stolen balls was the only significant $\mathrm{SC}$ variable, resembling in part with the component variables of discriminant models in the unbalanced and very unbalanced games (Table 4), except for the importance given to steals (defensive phase) in our study according to all discriminant analyses performed and compared to a greater weight given to throw/shot efficiency (offensive phase), as observed by Saavedra et al. (2017). Possibly, the differences obtained in our study may be attributed, in part, to the characteristics of the confrontations considered in this study, which was different from the procedures adopted by Saavedra et al. (2017).

Daza et al. (2017) identified variables related to victory prediction from the official statistics of the 2015 Men's WCh using a multiple logistic regression model. The authors found that the variables number of technical faults (less than 10), throws saved by the opponent's goalkeeper (less than 12 throws), goalkeeper efficiency (greater than or equal to 12 throws) and stolen balls (greater than five) increased, in that order, the odds of winning. Although these results refer to men, all the predictor variables of the logistic regression model, except for the opponent's goalkeeper efficiency, corroborate the defensive variables identified in our study for the balanced games and, in part, for the unbalanced games and very unbalanced games (Table 5).

However, the odds ratio for winning in this study is translated by the largest contribution of stolen balls, blocked throws and goalkeeper efficiency, thus differing from findings of Daza et al. (2017). Comparing our findings with those of Saavedra et al. (2017) and Daza et al. (2017), we can see that there is agreement on the importance of the defensive variables ST, BT and GE for both men and women, being indicators of a greater importance for the discrimination between the winning and losing teams. Perhaps, these findings should be associated with strength or mental vigor gained or added to success in stealing the ball, blocking or saving a throw, which alters interpersonal perception and ultimately influences individual physical and mental performance, reflecting itself in outcomes of games (Moesch \& Aplitzsch, 2012; Mortimer \& Edward, 2014). Thus, the team that has regained ball possession has a chance to attack again without the opponent having scored a goal (Mortimer \& Edward, 2014).
Based on the results of our research, we can feasibly highlight the importance of the goalkeeper given the identification of GE as a component variable of all victory predicting models; the goalkeeper is a key element of defensive performance. Although GE is a component of the model for the balanced games and does not have a significant $\mathrm{CE}$ in the analyses, a progressive increase in the contribution of this variable to the match outcome is observed with the increase in goal difference. In addition, the success of expert goalkeepers in save actions seems to be located in the delayed start into save movement in order to obtain more information about the ball's trajectory and in executing intervention actions in a shorter time (faster) than their less experienced colleagues (Schorer, 2005). Such findings reinforce the importance of goalkeepers' training aiming at the development of maximum strength and explosive strength (Aagaard, Simonsen, Andersen, Magnusson, \& Dyhre-Poulsen, 2002) and their ability to anticipate actions by identifying signals sent by attackers on the side and height of a throw on goal to decrease uncertainty (Guttiérrez-Davila, Rojas, Ortega, Campos, \& Párraga, 2011; Rojas, Gutiérrez-Davila, Ortega, Campos, \& Párraga, 2012).

There is a parallel between the game variables identified in the discriminant analyses and the principles of game in team sports (Bayer, 1994; Estriga \& Moreira, 2014). In the balanced games, the defensive principles of retrieving ball possession, hampering opponent's progression and protecting the own goal are observed to a certain extent in the identified variables ST, BT, and GE. On the other hand, offensive principles of maintaining ball possession, progression to goal and goal scoring are partially observed in the discriminant variables AE, TE, and TF. However, the variables identified for the balanced matches do not seem to clearly highlight both the defensive principle of hindering the opponent's progression (e.g., number of faults and punishments) and the offensive principle of progression to goal (e.g., duration and number of attacks ending in throws on goal and assists). In the unbalanced and very unbalanced games, the representation of the principles of the game by the identified variables is again verified, however, in the very unbalanced games, the principles of progression to goal (offensive) and hindering the opponent's progression to the target (defensive) are verified by a greater number of assists and aggressive tackles resulting in YC, respectively.

After the analysis of a game, coaches often have difficulties in interpreting and integrating the obtained information in the process of training planning. In this sense, coaches need to have a clear and desired game model, and they must develop steps and strategies to achieve it (Freitas, 2012). 
The here identified variables seem to offer a clear general idea of the winning team's game model, with a greater weight put on defensive behaviors, that manifest themselves in the defensive pressure on the opponents with the aim to regain possession of the ball as well as in protecting the goal, out of which actions, when successful, opportunities arise for quick transition to attack and scoring quick goals (counterattacks). If the opponents have managed to deny such transitions, possession of the ball must be preserved in order to seek for the situations with numerical and spatial advantages for shots from positional attacks; no loss of possession due to technical faults is wanted.

Additionally, the elaboration of game model is based on the choice of training tasks based on teaching approaches that emphasize complex interactions between teammates and opponents (Menezes, 2012). Therefore, during training sessions, it is important to emphasize game situations and teaching through games because they allow the delimitation of a tactical problem (with possibilities of restricting the space, number and functions of the players, and game rules); the tasks based on the game are required for the improvement of technical handball skills (simple situations contextualized), thus expanding players' understanding of the context and their ability to make decisions (Estriga \& Moreira, 2014; Menezes, Marques, \& Nunomura, 2017). Small-sided games with constraints on the invariant characteristics of the formal game (ball, goal, number of players, space, technical-tactical rules) also integrate the development of desired technical-tactical behaviors transferable to the formal game (Davids, Araújo, Correia, \& Vilar, 2013). However, the development of tasks should seek the desired skills of players aligned with the performance in competition. Tasks should be adequate to learning, consolidation and improvement phases of motor learning (Freitas, 2012).

It is also worth noting that, in the training planning process, factors such as competition experience, use of time-out, home team advantage, and quality of opposition, which are extremely important for the outcome of games, should also be accounted for (Prieto, et al. 2016; Teles \& Volossovitch, 2015). In order to ensure the players are to achieve an expert performance, practice time, participation in competitions, and number of toplevel games are the main tools used by coaches to characterize and analyze the development and process of sporting excellence (Deakin, Côté, \&
Harvey, 2009; Ericsson \& Charness, 1994; Ericsson, Krampe, \& Tesch-Romer, 1993).

For the studies with a result-oriented approach based on the summary of accumulated information, it should also be highlighted that, for some balanced games, it seems not possible to establish a direct relationship between the quantified actions and the game outcomes. In addition, it should be remembered that, although the system of cumulative game-observation variables used by the IHF has also been used in several studies, to our knowledge, this system lacks previous validation. Also, despite a great importance of defense and counterattack to the outcome of the game, the adopted variable system does not report the number of interruptions (fouls) caused by defensive actions, or the success of defensive sequences of obstructing counterattack favorable conditions when a team retreats to defense (Karcher \& Buchheit, 2014).

We recommend for future studies with the focus on women's handball noting the use of time-out, considering the quality of opposition in confrontations, and studying of sequences of technicaltactical actions carried out in balanced matches using techniques that allow dynamic approaches to the game. In addition, attention should be paid to how the information obtained in game reviews can guide coaches and technical committees in organizing and elaborating exercises and training sessions focused on problem solving and using them in the preparation of games according to the characteristics of confrontations.

In summary, among the variables identified by the discriminant methods, a greater weight was verified for the defensive variables stolen balls, blocked throws/shots and goalkeeper general efficiency, with a special emphasis on stolen balls; only then come the offensive variables: throw efficiency, attack efficiency and technical faults in balanced games. The games with the unbalanced and very unbalanced outcomes seem to follow the same tendency as the variables identified for the balanced games. However, for the very unbalanced games, the principles of progressing to the target (number of assists) and hindering the progression to the own target (yellow cards and 2-minute suspensions) are more commonly verified. The identified variables seem to provide a "general idea of the game model" based on the success of defensive behaviors in favoring and taking advantage of counterattacks or positional attacks with the fewest number of technical faults possible in high-level female handball, but other ideas on the game can be unfolded from the information obtained. 


\section{References}

Aagaard, P., Simonsen, E.B., Andersen, J.L., Magnusson, P., \& Dyhre-Poulsen, P. (2002). Increased rate of force development and neural drive of human skeletal muscle following resistance training. Journal Applied Physiology, 93, 1318-1326.

Agulló, J.J.E., Turpin, J.A.P., Olmedo, J.M.J., Tomás, A.P., \& Pueo, B. (2016). Effectiveness of male handball goalkeepers: A historical overview 1982-2012. International Journal of Performance Analysis in Sport, 16(1), 143-156.

Alexandru, E., \& Alexandru, A. (2009). The quantitative model of the finalizations in men's competitive handball and their efficiency. Journal of Physical Education and Sport, 24(3), 1-6.

Bayer, C. (1994). O ensino dos desportos colectivos. [The teaching of team sports. In Portuguese.] Lisboa: Dinalivro.

Bilge, M. (2012). Game analysis of Olympic, world and European championships in men's handball. Journal of Human Kinetics, 35(1), 109-118.

Davids, K., Araújo, D., Correia, V., \& Vilar, L. (2013). How small-sided and conditioned games enhance acquisition of movement and decision-making skills. Exercise and Sport Sciences Reviews, 41(3), 154-161.

Daza, G., Andrés, A., \& Tarragó, R. (2017). Match statistics as predictors of team's performance in elite competitive handball. Revista Internacional de Ciencias del Deporte, 48(13), 149-161.

Deakin, J.M., Côte, J., \& Harvey, A.S. (2009). Time, budgets, diaries, and analyses of concurrent practice activities. In K.A. Ericsson, P.J. Charness Feltovich \& R.R. Hoffman (Eds.), Expertise and expert performance (pp. 99-121). New York, NY: Cambridge University Press.

Ericsson, K.A., \& Charness, N. (1994). Expert performance: Its structure and acquisition. American Psychologist, 49(8), 725-747.

Ericsson, K.A., Krampe, R.T., \& Tesch-Romer, C. (1993). The role of deliberate practice in the acquisition of expert performance. Psychological Review, 100(3), 363-406.

Estriga, L., \& Moreira, I. (2014). Ensino do andebol na escola: Ensinar e aprender. [Teaching handball in school: Teaching and learning. In Portuguese.] Porto: Editora FADEUP.

Freitas, R. (2013). Da concepção ao modelo de jogo, do individual ao colectivo. [From conception to game model, from individual to collective. In Portuguese.] In M. Arraya \& P. Sequeira (Eds.), Andebol: um caminho para o alto rendimento (pp. 99-121). Lisboa: Editora Visões e Contextos.

Guttiérrez-Davila, M., Rojas, F.J., Ortega, M., Campos, J., \& Párraga, J. (2011). Anticipatory strategies of team-handball goalkeepers. Journal of Sports Sciences, 29(12),1321-1328.

Gruić, I., Vuleta, D., \& Milanović, D. (2006). Performance indicators of teams at the 2003 Men's World Handball Championship in Portugal. Kinesiology, 38(1), 164-175.

Karcher, C., \& Buchheit, M. (2014). On-court demands of elite handball, with special reference to playing positions. Sports Medicine, 44(6), 797-814.

Lagos, C., Gómez, M.A., Viaño, J., González-Garcia, I., \& Fernández, M. (2013). Home advantage in elite handball: The impact of the quality of opposition on team performance. International Journal of Performance Analysis in Sport, 13, 724-733.

Lorenzo, A., Gómez, M.Á., Ortega, E., Ibáñez, S.J., \& Sampaio, J. (2010). Game-related statistics which discriminate between winning and losing under-16 male basketball games. Journal of Sports Science and Medicine, 8(9), 664-668.

Massuça, L.M., Fragoso, I., \& Teles, J. (2013). Attributes of top elite team-handball players. Journal of Strength and Conditioning Research, 28(1), 178-186.

Meletakos, P., Vagenas, G., \& Byaios, I. (2011). A multivariate assessment of offensive performance indicators in men's handball: Trends and differences in the World Championships. International Journal of Performance Analysis in Sport, 11(2), 285-295.

Menezes, R.P. (2012). Contribuições da concepção dos fenômenos complexos para o ensino dos esportes coletivos. [Contributions from the design of complex phenomena to the teaching of team sports. In Portuguese.] Motriz, $18(1), 34-41$.

Menezes, R.P., Marques, R.F.R., \& Nunomura, M. (2017). Teaching handball to players under-12: The perspective of Brazilian coaches. Motriz, 23(4), 1-8.

Mingotti, S.A. (2013). Análise de dados através de métodos de estatística multivariada. [Data analysis using multivariate statistical methods. In Portuguese.] Belo Horizonte: Editora UFMG.

Moesch, K., \& Apitzsch, E. (2012). How do coaches experience psychological momentum? A qualitative study of female elite handball players. Sport Psychologist, 26(1), 435-453.

Mortimer, B. (2014). Does momentum exist in elite handball? International Journal of Performance Analysis in Sport, 14(3), 788-800.

Ohnjec, K., Vuleta, D., Milanović, D., \& Gruić, I. (2008). Performance indicators of teams at the 2003 World Handball championship for women in Croatia. Kinesiology, 40(1), 69-79.

Oliveira, T., \& Gomez, M. (2012). Effects of game location, period, and quality of opposition in elite handball performances. Perceptual and Motor Skills, 114(3), 783-794. 
Pfeiffer, M., \& Perl, J. (2006). Analysis of tactical structures in team handball by means of artificial neural networks. International Journal of Computer Science in Sport, 5(1): 4-14, 2006.

Prieto, J., Gómez, M.A., \& Sampaio, J. (2015). From a static to a dynamic perspective in handball match analysis: A systematic review. The Open Sports Sciences Journal, 8(1), 25-34.

Prieto, J., Gómez, M.Á., Volossovitch, A., \& Sampaio, J. (2016). Effects of team timeouts on the teams'scoring performance in elite handball close games. Kinesiology, 48(1), 115-123.

Rogulj, N., Srhoj, V., \& Srhoj, Lj. (2004). The contribution of collective attack tactics in differentiating handball score efficiency. Colleguium Antropologicum, 28(2), 739-746.

Rogulj, N., Vuleta, D., Milanovic, D., Cavala, M., \& Foretic, N. (2011). The efficiency of elements of collective attack tactics in handball. Kinesiologia Slovenica, 17(1), 5-14.

Rojas, F.J., Gutiérrez-Davila, M., Ortega, M., Campos, J., \& Párraga, J. (2012). Biomechanical analysis of anticipation of elite and inexperienced goalkeepers to distance shots in handball. Journal of Human Kinetics, 34(1), 41-48.

Saavedra, J.M., Porgeirsson, S., Kristjánsdóttir, H., Chang, M., \& Halldórsson, K. (2017). Handball game-related statistics in men at Olympic Games (2004-2016): Differences and discriminatory power. Retos, 32(2), $260-263$.

Seco, J.D.R. (2015). A historical update on handball game evolution throughout $20^{\text {th }}$ century. Revista de Ciencias del Deporte, 11(1), 3-38.

Schorer, J. (2005). Being right-on-time shows the sensory motor expertise of national team handball goalkeepers. Journal of Sport and Exercise Psychology, 27, 135.

Srhoj, V., Rogulj, N., Padovan, M., \& Katic, R. (2001). Influence of the attack end conduction on match result in handball. Collegium Antropologicum, 25(2), 611-617.

Teles, N., \& Volossovitch, A. (2015). Influência das variáveis contextuais no desempenho das equipes nos últimos 10 minutos do jogo de handebol. [Influence of contextual variables on team performance in the last 10 minutes of the handball game. In Portuguese.] Revista Brasileira de Educação Física e Esporte, 29(2), 177-187.

Tenenbaum, G., \& Driscoll, M.P. (2005). Methods of research in sport sciences: Quantitative and qualitative approaches. New York, NY: Meyer \& Meyer.

Volossovitch, A. (2013). Handball. In T. Garry, P. O’Donoghue \& J. Sampaio (Eds.), Handbook of sports performance analysis (pp. 380-392). New York, NY: Routledge.

Volossovitch, A. (2017). Research topics in team handball. In P. Passos, D. Araújo \& A. Volossovitch (Eds.), Performance analysis in team sports (pp. 200-217). New York, NY: Routledge.

Volossovitch, A., \& Gonçalves, I. (2003). The significance of game indicators for winning and losing team in handball. In E. Müller, H. Schwameder, G. Zallinger \& V. Fastenbauer (Eds.), Proceedings of the $8^{\text {th }}$ Annual Congress of European College of Sport Science (pp. 335). Salzburg: ECSS.

Vuleta, D., Milanovic, D., \& Sertic, H. (2003). Relations among variables of shooting for goal and outcomes of the 2000 Men's European Handball Championship matches. Kinesiology, 35(1), 168-83.

Vuleta, D., Sporis, G., \& Milanovic, D. (2015). Indicators of situational efficiency of winning and defeated male handball teams in matches of the Olympic tournament 2012. Acta Kinesiologica, 9(1), 40-49.

Submitted: November 24, 2018

Accepted: December 11, 2019

Published Online First: April 17, 2020

Correspondence to:

Leandro Vinhas de Paula

School of Physical Education, Physical Therapy and

Occupational Therapy,

Department of Sports, Federal University of Minas

Gerais - UFMG,

Av. Pres. Antônio Carlos, 6627 - Campus - Pampulha,

Belo Horizonte - MG, Brazil

Tel.: +55 (31) 35591989 / +55 (31) 993747564

E-mail: leandro59_educa@yahoo.com.br 